\title{
Benedito Nunes e o pensamento que se mundifica
}

\author{
Fábio Lucas \\ Universidade Federal de Minas Gerais. Belo Horizonte, Minas Gerais, Brasil
}

"Crivo de papel" (Nunes, 1998) reproduz o que há de mais denso e constante na obra de Benedito Nunes. $\bigcirc$ ponto de partida, seminal, é a Filosofia. A outra face do vasto campo de interesse do crítico constitui a Literatura. A sua preocupação mais envolvente é, na Filosofia, a obra de Heidegger, da qual tem sido, no Brasil, um dos mais autorizados analistas. No campo literário, ocupa-se primordialmente de Guimarães Rosa e Carlos Drummond de Andrade, sem descurar Fernando Pessoa, que lhe oferece sínteses adequadas e epígrafes às indagações filosóficas. E agrega, ainda, ao "Crivo de papel", penetrante e oportuno balanço da historiografia literária brasileira. Outros estudos se organizam no interior da obra, como a visão de Sócrates sob a vigilância de Valéry, a investigação da Música entre as Artes, e a exploração de temas como a História, a Ética, o Tempo e a Poesia.

"Crivo de papel", na primeira parte, que compreende dois terços do trabalho, visita e revisita o pensamento de Heidegger, no que este apresenta de mais instigante, quando propõe a confluência de Teologia e Filosofia. Na verdade, particulariza o que há de mais agudo nas digressões do filósofo alemão, não sem deixar à mostra os condicionamentos e as contradições que fazem vibrar a sua trajetória especulativa. Vê-se claramente o difícil caminho palmilhado por Heidegger no sentido de livrar-se da Teologia como fundamento da Filosofia e, após, de Deus, como razão primeira e, por último, de Cristo, como representação da verdade.

O tema, ventilado no primeiro ensaio, cresce de importância no segundo, "O último Deus" que, em realidade, não encerra a investigação. Antes, sugere o advento de nova manifestação de Deus. Uma espécie de "Second Coming" como se exprime no célebre poema de W. B. Yeats: "Surely Some Revelation is at Hand". Após citar Heidegger e o estudo Schelling, em que se diz "Toda Filosofia é Teologia" (...), e mencionar a Escolástica, Benedito Nunes sintetiza: "Teríamos, então, três Teologias: a neotestamentária do Deus encarnado, a natural do Theos, ente supremo representado como a causa, e a dos deuses, de subsistência narrativa mítica ou poética" (Nunes, 1998, p. 33).

Não se esgota aí o rico estudo de Benedito Nunes. No séquito do pensamento de Heidegger, mostra como, neste, "A Teologia cristã se apodera da Filosofia grega", pois se trata da "cristianização de uma teologia não cristã" (Nunes, 1998, p. 34). O autor de "Crivo de papel" ainda acrescenta: "Sintonizado à morte nietzshiana do Deus cristão, o ateísmo heideggeriano responsabilizaria o cristianismo como força coadjutora do niilismo, engrenada, na vertente da história moderna do ser, ao processo de secularização que trouxe a fuga dos deuses" (Nunes, 1998, p. 35).

Heidegger responsabiliza o cristianismo, ao expulsar do mundo os deuses pagãos, pela perda do Sagrado, pois a desdivinização Entgötterung promove a debandada dos deuses Flucht der Götter. E, a determinado momento, realiza a conexão da Arte com o Sagrado. Mas o principal argumento que Benedito Nunes ressalta em Heidegger constitui a vinda do último Deus, "cujo advento se subtrai à previsão e ao cálculo": "(...) ele se manifesta no aceno

LUCAS, Fábio. Benedito Nunes e o pensamento que se mundifica. Boletim do Museu Paraense Emílio Goeldi. Ciências Humanas, v. 6, n. 2, p. 447-449, maio-ago. 2011.

Publicado originalmente na "Revista da Academia Paulista de Letras", n. 119, em junho de 2003, São Paulo, SP. Os Editores agradecem a autorização para a reprodução do texto.

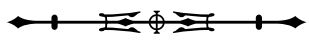


que lhe dá essência" (Nunes, 1998, p. 41). No fundo, o que se nota, em Heidegger, é a nostalgia de um Deus qualquer, como processo organizador da explicação do mundo. Mas, como pontua Benedito Nunes: "Do divino nada podemos predicar" (Nunes, 1998, p. 59).

Na sequência, em "Do primeiro ao último começo", Benedito Nunes explora ainda as indecisões de Heidegger, valendo-se inicialmente das críticas de Rüdiger Safranski, que acusa Heidegger de por em prática um "dadaísmo metafísico e teológico" (Nunes, 1998, p. 45).

No conjunto de trabalhos aglutinados sob o título "Poesia e Filosofia", Benedito Nunes nos oferece, em particular, uma análise da música perante a estética. Mostra que o século XVIII privilegiou a arte da palavra, a Literatura, que sempre supera a Música. Vale-se de Kant e Hegel, para, opondo-os, realçar a importância dessa última:

Vendo na Arte a manifestação sensível das idéias, Hegel valorizou a música em função dos mesmos aspectos que levaram Kant a rebaixá-la no conjunto da criação artística. Os sons, porque imateriais e fugidios, têm mais afinidade com o substrato espiritual da realidade, que é função da Arte manifestar, do que a pintura e a escultura (Nunes, 1998, p. 76).

O ensaio "Música, Filosofia e Literatura" é dos mais belos da coletânea. Termina reivindicando a função supraracional da Música, que se consagra como organizadora do Tempo.

Indo além, Benedito Nunes revela que "abstraindo-se esse ideal romântico, que esquecia tudo quanto a música tem de convencional para considerá-la uma espécie de fluxo cósmico, Schopenhauer abriu caminho à moderna fenomenologia da percepção da obra musical". E prossegue na análise, invocando o drama wagneriano e, a seguir, Baudelaire, Mallarmé e Verlaine: "Verlaine e Mallarmé quiseram estabelecer não apenas a convergência, mas também a coincidência entre Música e Poesia" (Nunes, 1998, p. 79).

O bloco seguinte trata de História e Filosofia, e começa pelos "Conceitos fundamentais da Metafísica". Curiosamente, as palavras que mais vigoram são o 'tédio' e a 'melancolia'. Mais uma vez, Heidegger está no centro, a discutir a crise do mundo moderno: ciência sem poder, arte sem aura, filosofia sem fundamento e religião impotente. O capítulo final "Tempo e História: introdução à crise" postula considerações ligadas ao título e invoca o testemunho de Kant:

\begin{abstract}
O homem é o sujeito dessa universalidade, que só pode vingar quando, ao agirmos, tomamos cada indivíduo e nós mesmos sempre com um fim e jamais como um meio (...) conseqüentemente a questão da unidade da espécie é prática, ética e política, e não histórico-teórica: ela concerne a um empenho pela autonomia moral e jurídica do homem, sujeito de um estado de direito e membro de uma comunidade internacional (Nunes, 1998, p. 152-153).
\end{abstract}

Para arrematar seu estudo, Benedito Nunes recorda a falência contemporânea de duas ideias: a do progresso e a da revolução.

O bloco posterior contempla "Leitura e críticas". Mais uma vez se encontram em evidência Heidegger e Kant. $\bigcirc$ autor indaga da natureza da Arte e apóia-se em Kant, para quem a Arte vem a ser "um querer que funda seus atos sobre a razão” (Nunes, 1998, p. 190).

O tema da Ética ocupa importante espaço na obra de Benedito Nunes. Há, em Heidegger, duas éticas, segundo Zeljko Loparic: uma, situacional do projeto, e outra, destinamental; ambas de habitar, de morar. A casa do ser, para Heidegger, é a linguagem. Curiosamente, Henriqueta Lisboa denominou "Pousada do Ser" uma de suas coletâneas de poemas. E, quando cuidamos do Deus filosófico, tão dolorosamente perdido, evocamos estes versos da poeta, em "Sofrimento ("Flor da morte", 1945-1949): "O que se perdeu foi pouco. Mas era o que eu mais amava".

Que dizer da especulação filosófica de Benedito Nunes? Além de apontar a crise da Filosofia, como o faz especificamente em "A Filosofia e o milênio", tem-se a sensação de transitar num labirinto. Louvem-se a beleza da exposição e a contribuição à estética, em especial nas questões sobre natureza da Arte, quando aborda o pensamento de Kant e Heidegger. No

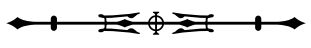


mais, são trabalhos mais expositivos do que conclusivos. $\mathrm{Na}$ linha de Heidegger, para quem "o mundo não é, mas se modifica" (Nunes, 1998, p. 114). É bem verdade que, no mesmo terreno, Santo Tomaz de Aquino acabou por desistir de fechar a Summa Theologiae e a Escolástica, depois de séculos de distingo e de explorar o axioma de que o conhecimento advém dos mananciais da razão e de revelação, e terminou por condenar-se à inanição. $O$ cristianismo trouxe uma antecipação teleológica extraterrena para escapar ao sonho racional da felicidade para todos dentro da finitude do ser humano. já a alternativa pragmática do pensar filosófico de Marx caiu, em alguns pontos, no campo da eficácia política em transformar o mundo, ficando à deriva as especulações sobre o ser.

A última parte de "Crivo de papel" incide na produção literária propriamente dita. $\bigcirc$ estudo sobre a histografia literária do Brasil é dos mais interessantes. Percorre os principais momentos do esforço historiográfico entre nós, com olhar crítico e desvendador. Aponta agudamente a contribuição do "contraditório movimento romântico", assinala a importância do Instituto Histórico e Geográfico Brasileiro e analisa as diferentes tentativas historiográficas até "A formação da Literatura brasileira" de Antonio Candido.

A seguir, Benedito Nunes publica um ensaio de admiração em "De Sagarana a Grande sertão: veredas". E conclui-se o "Crivo de papel" com o estudo "Aceitação da noite", acerca da poesia de Carlos Drummond de Andrade, em que se assinala, nela, além do lado solar, aquele, noturno, no qual se encena o drama da vida e a finitude humana. Acaba por explorar a "musa filosófica" do poeta mineiro. Portanto, na parte final da obra, Benedito Nunes se entrega mais à leitura interpretativa do que crítica. No aspecto meramente editorial do livro, passaram alguns cochilos tipográficos e à bibliografia faltou inserir Zeljko Loparic e Rüdiger Safranski. O autor, inexplicavelmente, cai na armadilha da palavra "reversão" por "inversão", muito popular hoje em dia (Nunes, 1998, p. 68). Nada disso desqualifica a obra, verdadeiramente ímpar na história e crítica de ideias.

\section{REFERÊNCIA}

NUNES, Benedito. Crivo de papel. São Paulo: Ática, 1998. 